\title{
Social organization and the maintenance of aggressive behavior in community-housed male Siamese fighting fish (Betta splendens)
}

\author{
NANCY WOODARD CAIN and RONALD BAENNINGER \\ Temple University, Philadelphia, Pennsylvania 19122
}

\begin{abstract}
The waning of aggressive behavior in two groups of community-housed male Betta was studied by observing incidences of display and fighting behaviors. In Experiment 1, observations were made during the establishment of a community, while it was maintained at a stable size, and during systematic removal of the dominant (alpha) males. Experiment 2 investigated the aggressive interactions of males in a stable-sized population, maintained for a period of 10 weeks. The results indicate that prolonged periods of constant conspecific exposure do not necessarily result in a significant attenuation of display behaviors. The data further indicate that the social organization (as determined from aggressive interactions) appears to be one in which the top- and bottom-ranking males are clearly defined. It is suggested that the maintenance of aggressive behavior among community-housed male Betta may well be related to their social position.
\end{abstract}

The aggressive behavior of adult male Siamese fighting fish is so intense that encounters often result in extensive physical damage. Consequently, Betta typically require physical isolation from one another. Simply viewing an opponent has been shown to be sufficient for the elicitation of aggressive behavior. An aggressive display may be readily elicited by the sight of another conspecific (Clayton $\&$ Hinde, 1968), the presentation of a mirror image (Baenninger, 1966), or by models of displaying conspecifics (Thompson, 1963). The frequency and intensity of these displays, which are characterized by gill-cover extension and fin erection, wane after prolonged exposure to such stimuli. The decrease in aggressive behavior observed following such visual exposure, however, does not generalize to situations involving physical combat (Lobb \& McCain, 1976; Meliska \& Meliska, 1976). The decrease in displaying may be stimulus specific (Baenninger \& Mattleman, 1973; Klein, Figler, \& Peeke, 1976), or it may reflect the lack of aversive consequences inherent in the manner of stimulation (Lobb \& McCain, 1976). Indeed, fish exposed to mirrors, models, and views of live conspecifics can neither attack, elude, nor drive their opponents away. Therefore, Rhoad, Kalat, and Klopfer (1975) have suggested that the decline in display responding may depend on an associative learning process in which the fish learns

Some of these data were reported by N.W.C. at meetings of the Eastern Psychological Association, 1977 and 1978. The authors thank P. Bersh, A. Leshner, L. Paul, and R. Rosnow for critical comments, D. Milne for advice on statistical analyses, and G. Smist for technical assistance. Address reprint requests to N. W. Cain, who is now at the Department of Psychology, Bucknell University, Lewisburg, Pennsylvania 17837. that attacking his "opponent" does not drive him away; the fish, in effect, comes to associate the stimuli of his "opponent" with their lack of consequences. Accordingly, if fish were allowed to interact freely with one another, then waning of display behaviors should not occur.

Aggressive behavior does not always wane over time when male Betta are allowed to interact freely. Lobb and McCain (1976) reported a complete waning of aggressive behavior among submissive fish following four 10-min paired encounters, but failed to find a corresponding decrease among their more dominant opponents. These paired encounters, however, may still present an artificial situation, since confrontation is forced and the ability of the loser to flee is limited to the confines of a small testing chamber. In fact, Baenninger (1966) has suggested that the reliability of social dominance among rats may be related to the manner in which it is tested; experimentally manipulated paired encounters result in formation of unreliable dominance hierarchies, whereas observations of naturally occurring aggressive encounters result in reliable dominance relationships.

Observations of naturally occurring aggressive behavior in a community of freely interacting Betta have shown a reduction in intense forms of aggressive behavior (actual physical combat) during initial fights for social rank (Goldstein, 1975). However, similar data on the rate of displaying have not been reported. In the present studies, dominance relations were studied by observing the occurrence of display and fighting behaviors for two groups of adult male Betta. In Experiment 1, observations were made during the establishment of a population, while it 
was maintained at a stable size, and during systematic removal of the top-ranking (alpha) males. Experiment 2 investigated the naturally occurring display and fighting behaviors of a group of male Betta maintained at a stable population size for 10 weeks.

\section{EXPERIMENT 1}

\section{Method}

Subjects. The subjects were six male Betta splendens, obtained from a local supplier and chosen on the basis of a healthy appearance. They were housed individually and visually isolated from one another for 2 weeks prior to testing.

Apparatus. A community of male Betta was established in a 206-liter glass aquarium measuring $140.4 \times 70.2 \times 70.2 \mathrm{~cm}$. The bottom of the aquarium was uniformly covered with fine gravel and planted with live vegetation. Overhead lighting was automatically timed for $16 \mathrm{~h}$ of light and $8 \mathrm{~h}$ of darkness. A filter in the tank, which provided aeration and filtration, ran continuously except during observation sessions. Water temperature was maintained between $26^{\circ}$ and $29^{\circ} \mathrm{C}$.

Procedure. The fish were introduced into the aquarium in a manner similar to that of Goldstein (1975). On the 1st day, two males of approximately the same size but different coloration were placed simultaneously into the far ends of the tank. If, within a 2-day period, a subordinate male was not identified or not completely intimidated, a third male was introduced into the tank. If the subordinate male was completely intimidated, he was removed and replaced by a new male. Complete intimidation was defined as prolonged immobility and the elimination of appetitive acts. Of the six fish introduced, only the second one had to be removed. The new fish were added at irregular intervals until a stable population of five was established. This procedure took a total of 2 weeks. It must be noted that neither in this experiment nor in Experiment 2 did the order of introduction appear to be related to eventual social positions. The five males comprising the population were: Aqua (A), Blue (B), Red $(R)$, Yellow (Y), and White (W). They were introduced in the order listed. Each fish was given a rank based on its computed initiator-to-recipient ratio. A rank for displays, chase/ fights, and a combination of these two measures (total aggressive encounters) was determined for each fish. Eighteen days after the introduction of the fifth male, the dominant (alpha) male was removed; his status was determined from the highest initiatorto-recipient ratio of displays and chase/fights among the five fish. Each week thereafter, the newly established alpha male was removed until the population was reduced to two fish.

Scan-sampling methods (Altmann, 1974) were used during two $1 / 2-h$ daily observation periods. A full scan of the aquarium, from left to right, was made every $60 \mathrm{sec}$ for each 30 -min period. During these scans, the behavioral state (displaying, chasing, being chased, etc.) of each fish was recorded. In addition to noting the initiator and recipient of each interaction, the experimenter also rated the quality of displays on a nominal scale of $1-3$, ranging from fin spread to full display, and the quality of chase/fights on a 1-3 scale, ranging from chasing to attack and physical damage. Between scans, observations were made of any postfight behaviors and the extent of any damage due to fighting. The two observation periods were separated by $3-4 \mathrm{~h}$ and were made at the same time daily.

\section{Results}

As shown in Figure 1, the social organization of the community studied appeared to be one in which a single male was clearly dominant. Figure 1 presents the initiator-to-recipient ratios of aggressive encoun-

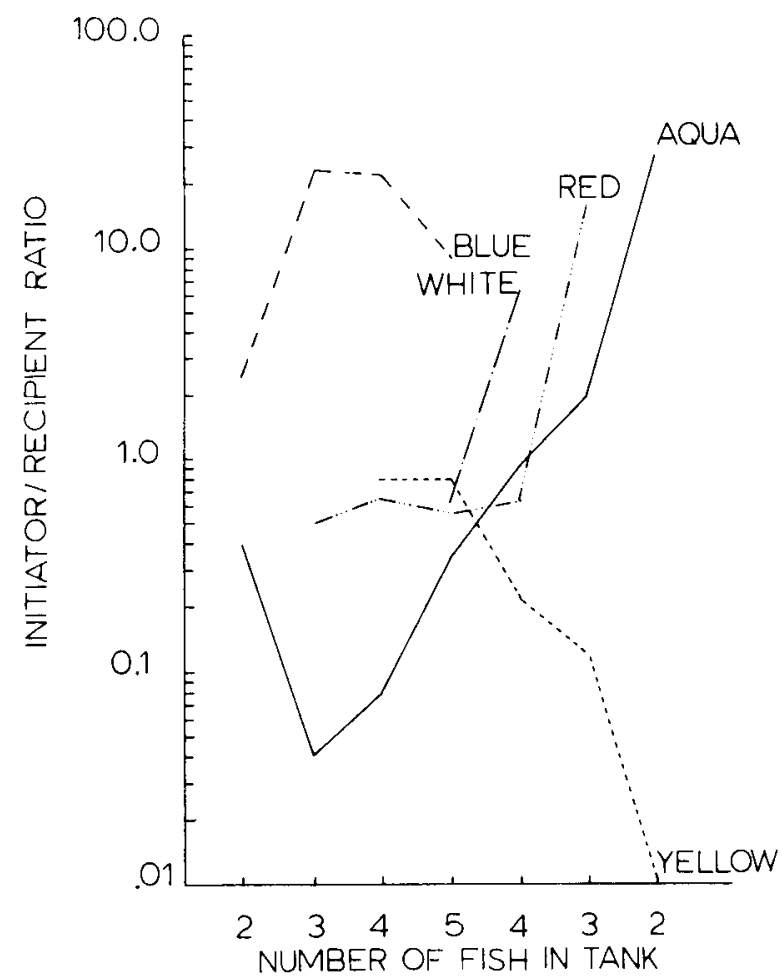

Figure 1. Ratio of the number of aggressive encounters initiated by each fish to the number received as a function of the number of fish in the community aquarium. Blue and Aqua were introduced first, followed by Red, Yellow, and White.

ters (displays plus chase/fights) for all fish as a function of increases and decreases in population size. The original alpha male maintained his dominant position as the population was increased from two to five fish. Additionally, the data indicate that a new alpha male reliably emerged when the already established alpha male was removed. A Wilcoxon test performed on the initiator-to-recipient ratios of males during the week before and the week after they became alpha males indicates that this effect was statistically significant $(T=0, p<.05)$.

Following addition of the fifth male, the population size was maintained at five fish for 19 days. Figure 2 presents data for the number of initiations of display and fighting behaviors during Days 8-19 of this period (the first data points are the frequency of displays and chase/fights 1 week after the introduction of the last male). As a group, neither display initiations nor chase/fight initiations decreased significantly when the population was maintained at a stable size. Trend tests performed on the data indicated that the linear, quadratic, and cubic trends over observation periods were not significant for displays or chase/fights [all Fs $(1,20)<1$ ]. However, $t$ tests performed on the differences between the first and last observation periods indicated that there was a significant difference for chase/fights $[\mathrm{t}(4)=4.75$, $\mathrm{p}<.01$ ], but not for displays [t(4) $=-1.87, \mathrm{p}>.05]$. The decrease in chase/fights can be observed in the 


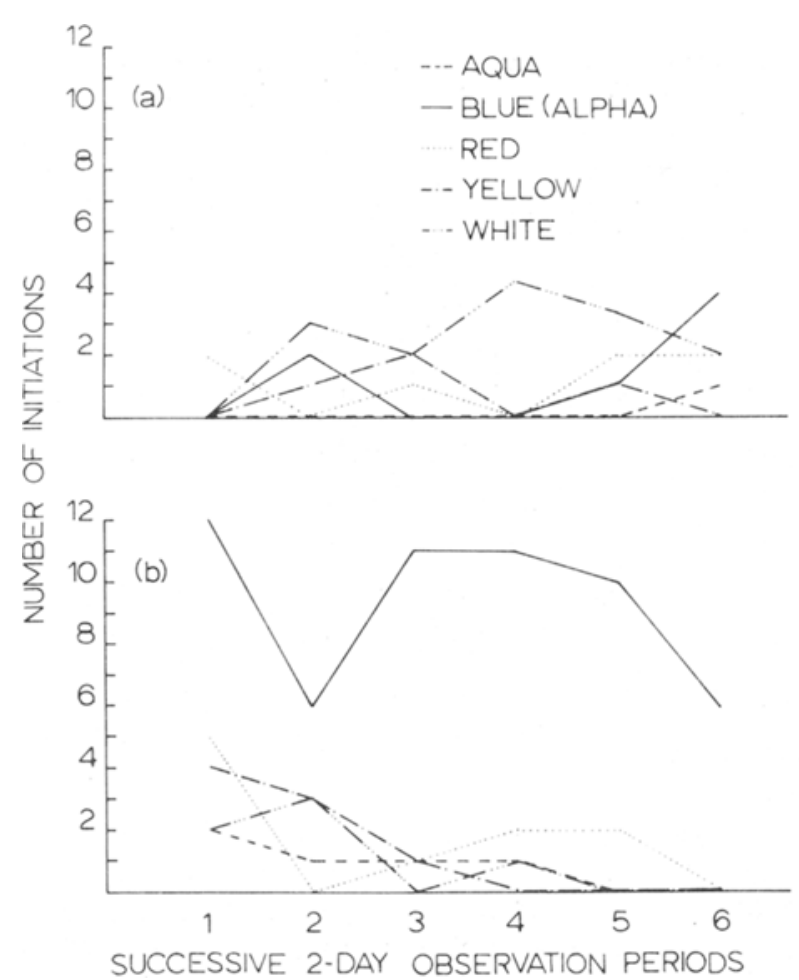

Figure 2. Number of initiations of displays (a) and chase/ fight encounters (b) over 12 days during which the population size was maintained at five fish. Blue and Aqua were introduced first, followed by Red, Yellow, and White.

figure. Additionally, the figure shows that the original alpha male (Fish B) initiated far more chase/ fight initiations than lower ranking males.

\section{EXPERIMENT 2}

Although, as a group, displays did not wane significantly in Experiment 1, it might be argued that increases and decreases in population size do not allow for the establishment of socially stable relationships; these changes in group membership may serve to reinforce social interactions (Guhl, 1968). Therefore, Experiment 2 was designed to observe the aggressive interactions of males in a stable-sized population, maintained for a period of 10 weeks.

\section{Method}

Subjects. The subjects were nine adult male Siamese fighting fish, obtained from a local supplier and chosen on the basis of a healthy appearance. They were housed individually and visually isolated from one another for 2 weeks prior to testing.

Apparatus. The community tank setup and the experimental conditions were the same as those described in Experiment 1 .

Procedure. The fish were introduced into the tank following the same procedure outlined in Experiment 1. Of the nine fish introduced, three were removed during the 1st week. The six males comprising the population were: Blue (1), Dark (2), Aqua (3), Purple (4), Turquoise (5), and Red (6). They were introduced into the tank in the order listed. Observations were made daily, during the $1 / 2 \mathrm{~h}$ following the introduction of a new male and at the same time thereafter for a total of 12 weeks. Data were recorded for the stable-sized community for 10 weeks from the day the last male (6) was introduced. Scan-sampling methods, as described in Experiment 1 , were used during the $1 / 2-h$ daily observation sessions.

\section{Results}

The results indicate that the overall group fluctuations in the frequency of displays during the 9 weeks of observation were not in the direction of a decreased frequency of displaying (see Figure 3). Figure 3 presents the mean frequency of displays and chase/fights for each week of the 9 weeks of observation. Trend analyses performed on the group means indicated insignificant linear, quadratic, and cubic trends across the nine observation periods for displays [all $\mathrm{Fs}(1,40)<1]$. Although an overall significant difference was found between observation periods for the display measure $[F(8,40)=3.78$, $p<.05$ ], Tukey tests performed on the individual observation period means indicate that neither the increase from Day 3 to Day $4(Q=.97, p>.05)$ nor the increase from Day 5 to Day $6(Q=2.35$, $p>.05$ ) was significant. It may be noted in the figure that chase/fights appear to decrease in a more systematic fashion over the nine periods of observation; however, the linear, quadratic, and cubic trends were found to be insignificant [all $\mathrm{Fs}(1,40)<1, \mathrm{p}\rangle .05]$.

The individual data indicate that for two fish (6 and 3) there was a significant linear decrease in the frequency of displays over the 9 observation weeks $(r=-.69, r=-.84 ; p<.05)$. A significant linear decrease in chase/fights was found in these fish as well $(r=-.85, r=-.77 ; p<.05)$. The data for these two fish indicated that the target behaviors decreased rapidly as the slopes of the best

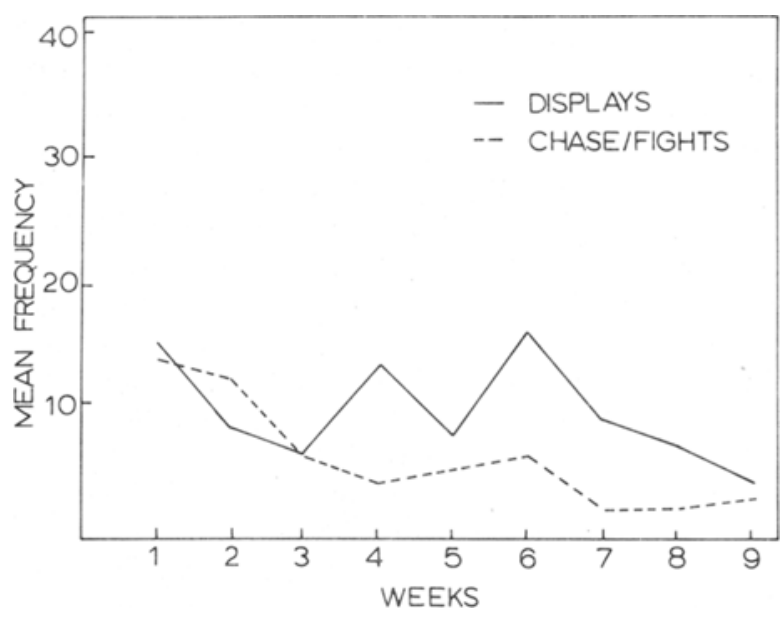

Figure 3. Mean frequency of displays and chase/fights over 9 weeks of observation. The first data points are the mean frequency of displays and chase/fights 1 week after introduction of the last male. 
fitting straight lines were -1.5 and -2.5 , respectively, for displays and -1.6 and -4.7 for chase/ fights.

Full displays, which were recorded as a 3 on the nominal scale of display quality, were observed during each of the 10 weeks. Fighting with physical damage or chase/fights of intensity 3 were never observed during any of the observation sessions except during the 1st week following introduction of the last male. However, some evidence of physical damage was observed at the onset of daily scansampling observations, apparently reflecting some fighting between observation sessions. These wounds and fin tissue damage were first observed during the 5 th week, or 6 weeks from the day that the last male was introduced into the tank; they were observed weekly thereafter until observations were terminated.

The ratio of the total number of display and chase fight initiations to the total number of displays and chase/fights received by each fish was used as an index of dominance. Each fish was given a weekly rank based on its computed initiator-to-recipient ratio (I/R). The smallest $I / R$ ratio indicated the omega or bottom-ranking male, whereas the largest ratio indicated the alpha or top-ranking male. A rank for displays, chase/fights, and a combination of these two measures (total aggressive encounters) was determined for each fish over the 10 weeks of observation. Friedman two-way ANOVA (Siegel, 1956) were performed on these ranks and indicated that the reliability of these orders over time was greater than would be expected by chance $(p<.001$ for all measures).

The data further indicate that the social organization of the community studied appears to be one in which the alpha and omega male figures are clearly defined and in which all other midranking males are of comparable social status. These data are shown in Table 1. The alpha male alone accounted for $50 \%$ of the total chase/fights and $24 \%$ of display initiations, whereas the omega male accounted for only $7 \%$ and $3 \%$, respectively. A percentage of 16.7 for both measures would be expected. The $1 / \mathrm{R}$ ratios for chase/fights, in particular, also indicate that the alpha and omega figures were clearly defined. The $I / R$ ratio for the alpha male was at least six times larger than any other midranking male; for the omega male, it was four times smaller than any other midranking male.

In summary, the results indicate that the group frequency of display initiations and chase/fight initiations does not wane significantly over 9 weeks of observation. The data further show that displays and chase/fights wane in a linear fashion for specific fish. Additionally, the data indicate that actual physical combat was not observed after the 1 st week
Table 1

Initiator/Recipient (I/R) Ratios, Rank, and Percent of Total Initiations for Display and Chase/Fight Measures

\begin{tabular}{|c|c|c|c|c|c|}
\hline Fish & $\begin{array}{r}\text { Number } \\
\text { Initiated }\end{array}$ & $\begin{array}{l}\text { Number } \\
\text { Received }\end{array}$ & $\begin{array}{c}\text { Percent of } \\
\text { Total } \\
\text { Initiations }\end{array}$ & $\begin{array}{c}\mathrm{I} / \mathrm{R} \\
\text { Ratio }\end{array}$ & Rank \\
\hline \multicolumn{6}{|c|}{ Displays } \\
\hline 1 & 119 & 153 & 16.5 & .78 & 5 \\
\hline 2 & 47 & 97 & 6.5 & .48 & 6 \\
\hline 3 & 173 & 116 & 24.0 & 1.50 & 1 \\
\hline 4 & 142 & 143 & 20.0 & .99 & 4 \\
\hline 5 & 117 & 110 & 16.0 & 1.06 & 3 \\
\hline 6 & 123 & 102 & 17.0 & 1.20 & 2 \\
\hline \multicolumn{6}{|c|}{ Chase/Fights } \\
\hline 1 & 39 & 68 & 8.5 & .57 & 4 \\
\hline 2 & 13 & 107 & 3.0 & .12 & 6 \\
\hline 3 & 229 & 44 & 50.5 & 5.20 & 1 \\
\hline 4 & 42 & 81 & 9.0 & .52 & 5 \\
\hline 5 & 72 & 83 & 16.0 & .86 & 2 \\
\hline 6 & 57 & 69 & 13.0 & .82 & 3 \\
\hline
\end{tabular}

Note-Values are computed from all 10 weeks of observation.

of observation, but there was some evidence of wounds following the 5th week of observation. Finally, the data suggest that the social organization of the community studied appears to be one in which the top- and bottom-ranking male figures are clearly defined.

\section{DISCUSSION}

The results of these two studies suggest that prolonged periods of constant conspecific exposure do not necessarily result in a significant attenuation of display behaviors among groups of communityhoused male Betta. However, the results of Experiment 2 suggest that this is true only if the data are considered as a whole. Display behaviors do wane significantly for specific fish; significant decreases were observed for the top-and one midranking male. These results are consistent with Lobb and McCain's (1976) findings in emphasizing the differences between actual combat and mutual viewing procedures. Combat situations involve both visual exposure and the consequences of aggressing (as in the present studies), whereas mutual viewing situations preclude aversive stimulation. Previous studies using simply mutual viewing techniques have reported that the display wanes significantly with as little as $5 \mathrm{~h}$ of constant exposure to display-eliciting stimuli (Peeke \& Peeke, 1970).

The findings of these two studies argue against the hypothesis that constant conspecific exposure results in habituation of the threat display (Peeke \& Peeke, 1973). However, most studies on the habituation of threat displays in Betta have defined constant conspecific exposure as continual or prolonged visual exposure and have used mirrors, models, and the 
opportunity to view live conspecifics as reinforcers. Unlike fish in an unrestrained seminaturalistic environment, fish in these situations cannot attack, elude, or drive their opponents away. Rhoad et al. (1975) have suggested that the waning of the threat display in these situations may reflect the fact that the experimental fish comes to associate the stimuli of its opponent with a lack of consequences for aggressing. The fact that the fish in the present study did not show a decrement in responding characteristic of studies involving visual exposure alone provides indirect support for Rhoad et al.'s (1975) associative learning hypothesis.

The finding in Experiment 2 that although the overall group frequency of displays and chase/fights did not wane significantly, the individual frequencies of two of the fish did wane is an interesting one. It is even more interesting to note that one of these was the alpha, or top-ranking, male. Several explanations have been offered for such decreases in aggressive behavior; however, none sufficiently explains the present results. For example, Goldstein (1975) attributes the reduction in fighting behavior of community-housed Betta to the diminished releasing capacities of submissive fish following the establishment of dominance-subordinate relationships. No significant decreases in displays or chase/ fights were found for the bottom-ranking male in Experiment 2; however, it is likely that this fish's overall low rate of any aggressive behavior made it difficult to see a trend. The results of the present study extend Goldstein's finding by suggesting that the overall reduction in aggressive behavior may be attributable to decreases in aggressive behavior by the alpha male as well.

Another hypothesis (Scott \& Fredericson, 1951) suggests that a decrease in aggressive behavior occurs because the establishment of dominance results in a lack of reinforcement for aggressive behavior. It is not, however, that the alpha male is no longer reinforced for aggressive behavior. Indeed, displays and chases by the alpha male continued to be reinforced by withdrawal of the opponent.

Why, then, does the establishment of dominance result in the attenuation of display and chasing behaviors? It is not because the alpha male fails to be reinforced for aggressive behavior. Rather, it appears that displays and chases are no longer necessary to maintain his clearly dominant position. In other words, when responding is no longer necessary for reinforcement, the response wanes (Davenport, Coger, \& Spector, 1970; Davenport \& Olson, 1968). It is likely that other behaviors emerge, perhaps through being reinforced, which are not overtly aggressive, yet accomplish the same goal.
The results of the present experiments further suggest that the social organization of communityhoused Betta, as determined from their aggressive interactions, appears to be one in which a single male is clearly dominant, with most others below him being of comparable social status. The results of Experiment 2 suggest that the bottom-ranking male or the omega figure is clearly defined as well. The presence of a clearly dominant male has also been observed in Poecilia (Gorlick, 1976), Platypoecilus (Braddock, 1945), and Xiphophorus (Noble, 1939). The existence of this form of social organization in community-housed male Betta is further confirmed by data in Experiment 1 which show that a new alpha male reliably emerges upon removal of the former alpha male. A similar finding has been reported in cockerels (Salamon, Lazorcheck, \& Schein, 1966) and in sunfish (Greenberg, 1947).

Thus, the results of these two studies suggest that the maintenance of aggressive behavior among community-housed male Betta may well be related to their social position. Both the top- and bottomranking males appear to have clearly defined social positions. The aggressive behavior (both displays and chase/fights) of the bottom-ranking males is most likely suppressed because they are punished for aggressing. In contrast, the initially high level of aggressive behavior observed by the alpha, or topranking, male drops off rapidly once dominance has been established. It is suggested here that the alpha male's decrease in displays and chase/fights reflects the fact that these behaviors are no longer necessary to maintain its clearly dominant social position.

\section{REFERENCES}

Altmann, J. Observational study of behavioral sampling methods. Behaviour, 1974, 49, 227-268.

BAENNINGER, L. P. The reliability of dominance orders in rats. Animal Behaviour, 1966, 14, 367-371.

BAEnNinger, R. Waning of aggressive motivation in Betta splendens. Psychonomic Science, 1966, 4, 241-242.

Baenninger, R., \& Mattleman, R. Visual reinforcement: Operant acquisition in the presence of a free mirror. Animal Learning \& Behavior, 1973, 1, 302-306.

Braddock, J. C. Some aspects of the dominance-subordination relationship in the fish Platypoecilus maculatus. Physiological Zoology, 1945, 18, 176-195

Clayton, F. L., \& Hinde, R. A. The habituation and recovery of aggressive display in Betta splendens. Behaviour, 1968, 30, 96-106.

Davenport, D., Coger, R., \& Spector, N. The redefinition of extinction applied to Sidman free-operant avoidance responding. Psychonomic Science, 1970, 19, 181-182.

Davenport, D., \& Olson, R. A reinterpretation of extinction in discriminated avoidance. Psychonomic Science, 1968, 13, 5-6.

Golostein, S. R. Observations on the establishment of a stable community of adult male and female Siamese fighting fish (Betta splendens). Animal Behaviour, 1975, 23, 179-185. 
GoRlick, D. L. Dominance hierarchies and factors influencing dominance in the guppy Poecilia reticulata (Peters). Animal Behaviour, 1976, 24, 336-346.

GreenBerg, B. Some relations between territory, social hierarchy, and leadership in the green sunfish. Physiological Zoology, 1947, 20, 267-299.

Gu1t, A. M. Social intertia and social stability in chickens. Animal Behaviour, 1968, 16, 219-232.

Klein, R. M., Figler, M. H., \& Peeke, H. V. S. Modification of consummatory (attack) behavior resulting from prior habituation of the appetitive (threat) components of the agonistic sequence in male Betta splendens (Pisces, Belontiidae). Behaviour, 1976, 58, 1-25.

LoBB, M. L., \& McCaIn, G. Procedurally related differences in the aggressive behavior of Betta splendens (Regan). Animal Learning \& Behavior, 1976, 4, 367-373.

Mrisiska, J. A.. \& Meliska, C. J. Effects of habituation on threat display and dominance establishment in the Siamese fighting fish (Betta splendens). Animal Learning \& Behavior, 1976, 4, 167-171.

NoBle, G. K. The experimental animal from the naturalist's point of view. American Naturalist, 1939, 73, 113-126.

Pefke, H. V. S., \& Peeke, S. C. Habituation of conspecific aggression responses in the Siamese fighting fish (Betta splen- dens). Behaviour, 1970, 36, 232-245.

Preke, H. V. S., \& Pekke, S. C. Habituation in fish with special reference to intraspecific aggressive behavior. In H. V. S. Peeke \& M. J. Herz (Eds.), Habituation I: Behavioral studies. New York: Academic Press, 1973.

Rhoad, K. D., Kalat, J. W., \& Klopfer, P. H. Aggression and avoidance by Betla splendens toward natural and artificial stimuli. Animal Learning \& Behavior, 1975, 3, 271-276.

Salamon, A. L., Lazorcheck, M. J., \& Schein, M. Effect of social dominance on individual crowing rates of cockerels. Journal of Comparative and Physiological Psychology, 1966, 61, 144-146.

Scott, J. P., \& Fredericson, E. The causes of fighting in mice and rats. Physiological Zoology, 1951, 24, 273-309.

Sifigi, S. Nonparametric statistics. New York: McGraw-Hill, 1956.

THompson, T. Operant and classically-conditioned aggressive behavior in Siamese fighting fish. American Zoologist, 1963, $6,629-641$.

(Received for publication January 25, 1979; revision accepted June $11,1979$. 